\title{
An in-vitro model for studying the interaction of Escherichia coli 0157:H7 and other enteropathogens with bovine primary cell cultures
}

\author{
M. P. DiBb-Fuller, A. BeSt*, D. A. StAGG, W. A. COOlEy and M. J. WOODWARD
}

Veterinary Laboratories Agency (Weybridge), Woodham Lane, Addlestone, Surrey KT15 3NB and *Division of Biochemistry and Molecular Biology, School of Biological Sciences, University of Southampton, Bassett Crescent East, Southampton SO16 7PX

\begin{abstract}
Sections of kidney, trachea, ileum, colon, rectum and rumen were removed at post mortem from a neonatal calf and, with the exception of the rumen, primary cell lines were established for each of the cell types. The adherence of enterohaemorrhagic Escherichia coli (EHEC) serotype O157:H7, enteropathogenic E. coli (EPEC) serotype O111, E. coli K12 (a laboratory adapted non-pathogenic strain) and Salmonella enterica serotype Typhimurium was assayed on each cell type. For all adherence assays on all cell lines, EHEC 0157:H7 adhered to a significantly greater extent than the other bacteria. $S$. Typhimurium and EPEC 0111 adhered to a similar extent to one another, whereas $E$. coli K12 was significantly less adherent by 100 -fold. In all cell types, $>10 \%$ of adherent $S$. Typhimurium bacteria invaded, whereas $c .0 .01-0.1 \%$ of adherent EHEC 0157:H7 and EPEC 0111 bacteria invaded, although they are regarded as non-invasive. EHEC 0157 generated actin re-arrangements in all cell types as demonstrated by fluorescent actin staining (FAS) under densely packed bacterial micro-colonies. EPEC O111 readily generated the localised adherent phenotype on bovine cells but generated only densely packed micro-colonies on HEp-2 cells. The intensity of actin re-arrangements induced in bovine cells by EPEC 0111 was less than that induced by EHEC O157:H7. The intimate attachment on all cell types by both EHEC 0157:H7 and EPEC 0111 was clearly demonstrated by scanning electron microscopy.
\end{abstract}

\section{Introduction}

Enterohaemorrhagic Escherichia coli (EHEC) serotype O157:H7 infection of man is a food-borne zoonosis of considerable current public concern. Infection is associated with a distinctive gastrointestinal illness of severe bloody diarrhoea without fever, termed haemorrhagic colitis (HC), first described by Riley et al. [1]. Sequelae may include acute renal failure, thrombocytopenia and micro-angiopathic haemolytic anaemia, designated haemorrhagic uraemic syndrome (HUS), first recognised by Karmali et al. [2]. Infection is potentially fatal in the elderly and the very young and major incidents in the USA, Japan and the UK have been documented [3-5].

Received 23 Nov. 2000; revised version received 2 April 2001; accepted 2 April 2001.

Corresponding author: Professor M. J. Woodward (e-mail: M.J.woodward@vla.defra.gov.uk).
Molecular pathogenesis studies of EHEC O157:H7 indicate that virulence determinants and their regulatory factors are encoded by the chromosome, a $60-\mathrm{Mda}$ plasmid and by toxin-converting bacteriophage [6]. The role of fimbriae in adherence remains unclear [7-9]. Transfer of the pO157 60-Mda plasmid to E. coli K12 resulted in elaboration of a novel fimbria by $E$. coli K12 and enhanced adherence to intestinal cells [7]. Other studies have demonstrated that $\mathrm{O} 157$ isolates without plasmids adhere to Henle-407 cells and that most $\mathrm{O} 157$ isolates are non-fimbriate $[10,11]$. The principal factors for E. coli $\mathrm{O} 157$ colonisation and adherence to the intestinal epithelium are intimin and the signal transduction apparatus. Intimin is an outermembrane protein of $94-97 \mathrm{kDa}$ which is encoded by the eae $A$ gene located within a chromosomally encoded pathogenicity island [12]. The signal transduction apparatus comprises a number of secreted proteins (EspA) that form a filament and a pore in the enterocyte (EspB and D) to deliver the Tir effector protein in to the enterocyte [13-15]. The result is intimate attachment of the bacterium to the enterocyte 
surface mediated by bacterial docking proteins with actin re-arrangements causing pedestal formation and consequent effacement of villi.

EHEC O157:H7 are present in the faecal flora of a number of animals including cattle, sheep, goats, pigs, dogs, cats, chickens and gulls, with the primary source of infection for man considered to be cattle and bovine-derived meat products [16]. In conventional and gnotobiotic pigs, EHEC O157:H7 produces extensive 'attaching and effacing' lesions, whereas eaeA mutants defective for the elaboration of intimin failed to colonise $[12,17,18]$. Calves and older cattle may be readily infected with $E$. coli $\mathrm{O} 157: \mathrm{H} 7$, both naturally and experimentally, with mild transient diarrhoea in calves and an asymptomatic transient carrier status in older animals [19]. The bacterium may persist in cattle for many months, but generally persists for about 30 days or less $[20,21]$. In experimental infections, DeanNystrom et al. [22, 23] showed that with a dose of $10^{10} \mathrm{cfu}$ of a five-strain mixture of EHEC O157:H7, normal neonatal calves of $12-36 \mathrm{~h}$ of age gave attaching and effacing lesions in both small and large intestines and lesions were detectable in the rectum of 3-month-old weaned calves. These data indicate that the mechanisms for intimate attachment encoded by the locus of enterocyte effacement of EHEC O157:H7 do mediate mucosal colonisation in bovines. However, there is still little evidence for mucosal colonisation of naturally infected bovines.

Studies are underway in this laboratory to investigate the mechanisms by which EHEC O157:H7 persists in the bovine gastrointestinal tract. This paper describes the derivation of bovine primary cell cultures for adherence assays.

\section{Materials and methods}

\section{Bacterial strains and inocula}

EHEC O157:H7 strain $\mathrm{VT}^{-}$(NCTC 12900) was confirmed by gene probe analysis to possess eaeA, sep $\mathrm{ABCD}, \operatorname{esp} \mathrm{A}, \operatorname{etp} \mathrm{D}, k a t \mathrm{P}$ and hly $\mathrm{A}$ and to lack genes encoding VT1 and VT2. Southern hybridisation of the strain NCTC 12900 plasmid profile confirmed the presence of hlyA on a plasmid c. $60 \mathrm{MDa}$ in size, assumed to be the highly conserved pO157 plasmid, and no other plasmids were observed. Enteropathogenic E. coli serotype O111 strain NM:B171 was isolated from an infant with diarrhoea [24] and was kindly provided by Professor Gordon Dougan (Imperial College, University of London). Salmonella enterica serotype Typhimurium DT104 strain 3530 was a bovine isolate obtained from the reference collection at the Veterinary Laboratory Agency (Weybridge) (Addlestone, Surrey). E. coli K12 strain DH5 $\alpha$ was from a commercial source (Gibco-BRL). All bacteria were maintained on Dorset's egg medium at room temperature. To prepare inocula, each strain was streaked to single colonies on Blood Agar (Oxoid) and a sweep of up to 20 colonies was taken into nutrient broth and grown overnight at $37^{\circ} \mathrm{C}$. Numbers of viable bacteria were determined by serial dilution and plating on to nutrient agar. Confirmation of the serotype of bacteria recovered from these experiments was by slide agglutination with appropriate sera (VLA, Weybridge).

\section{Development of primary bovine cell lines}

Sections of the alimentary tract including the rumen, ileum, colon and rectum, and also trachea and kidney were removed aseptically from a necropsied calf that had been taken at birth and deprived of colostrum. Tissues were treated separately. Sections of ileum, colon and rectum were tied at one end with sterile catgut and the luminal surface was washed three times with pre-warmed Ringer's solution before adding $5 \mathrm{ml}$ of Accutase (Tissue Culture Services, Botolph Claydon, Bucks) to enzymically detach the outer layer of cells. After incubation for $60 \mathrm{~min}$ at $37^{\circ} \mathrm{C}$, the Accutase was removed and centrifuged at $100 \mathrm{~g}$ for $5 \mathrm{~min}$. The resulting pellets were washed twice in Ringer's solution and resuspended in complete tissue-culture medium containing L-glutamine (Sigma) $1 \%$ non-essential amino acids (NEAA; Sigma) $1 \%$ fetal calf serum (FCS; Sigma) $10 \%$ and gentamicin (Sigma) $50 \mathrm{mg} / \mathrm{L}$ in Eagle's Minimal Essential Medium (MEM; Sigma). For the rumen, small pieces $\left(c .1 \mathrm{~cm}^{2}\right)$ of tissue were prepared and the top layer of cells was scraped into pre-warmed Ringer's solution. The cell preparation was passed through a coarse mesh to remove excess tissue and the cell suspension was centrifuged at $100 \mathrm{~g}$ for $5 \mathrm{~min}$. The pellet was resuspended in Accutase and the cells were digested for $60 \mathrm{~min}$ at $37^{\circ} \mathrm{C}$. Cells were pelleted by centrifugation and resuspended in complete tissue-culture medium.

The trachea was cut into small rings (c. 5-mm lengths) and bathed in complete medium, whereas a cell suspension was prepared from the bovine kidney by the method described by Youngner [25]. All tissue preparations were placed in eight-well tissue-culture plates (Nunc) and incubated at $37^{\circ} \mathrm{C}$ at $95 \%$ humidity; the normal air phase was supplemented with $\mathrm{CO}_{2} 5 \%$. The primary cells were lightly trypsinised every second day to selectively remove fibroblasts. At the earliest opportunity the primary cells were detached enzymically from the tissue-culture plastic, suspended in cryopreservation medium (dimethyl-sulphoxide 8\% FCS $92 \%$ and secured in liquid nitrogen. A seed stock of 10 vials was prepared from each cell type that had grown in vitro.

\section{Cells}

HEp-2 cells were obtained from the European Collection of Animal Cell Cultures (ECACC, Salisbury). Transformed and primary cell types were maintained in complete medium in $75-\mathrm{cm}^{2}$ flasks at $37^{\circ} \mathrm{C}$ in air with 
$\mathrm{CO}_{2} \quad 5 \%$ and passaged twice weekly. To suspend, the cells were washed and then incubated in Accutase for $15 \mathrm{~min}$ at $37^{\circ} \mathrm{C}\left(\mathrm{CO}_{2} 5 \%\right)$. For confluent monolayers, 24-well tissue-culture plates were seeded with $1 \times 10^{5}$ cells/well and incubated for 2 days at $37^{\circ} \mathrm{C}$ $\left(\mathrm{CO}_{2}\right.$ 5\%). Confluent monolayers contained (4-6) $\times$ $10^{5}$ cells/well.

\section{Association and invasion assays}

Tissue-culture assays were performed by the method described previously [26]. Briefly, duplicate plates containing confluent monolayers of cells were washed in Hanks's Balanced Salts Solution (HBSS; Sigma) and $1 \mathrm{ml}$ of incomplete medium, containing NEAA $1 \%$, L-glutamine 1\% and EMEM 98\% was added per well. The monolayers were infected with $10 \mu \mathrm{l}$ of the inoculum as described above containing $c .1 \times 10^{7}$ viable bacterial cells and the monolayers were incubated for $3 \mathrm{~h}$ at $37^{\circ} \mathrm{C}\left(\mathrm{CO}_{2} 5 \%\right)$. For the association assay, the monolayers were washed six times with HBSS before disrupting with Triton (Sigma) 1\% v/v. Numbers of bacteria (cfu) were determined by plating on to nutrient agar. Association is reported as a combination of adhering and invading bacteria.

For invasion, the assay was performed as described for the association assay, but after allowing the bacteria to associate with the monolayer, wells were washed three times in HBSS before adding EMEM containing gentamicin $100 \mathrm{mg} / \mathrm{L}$ to kill bacteria external to the cells. Monolayers were incubated at $37^{\circ} \mathrm{C}\left(\mathrm{CO}_{2} 5 \%\right)$ for $2 \mathrm{~h}$, washed twice, disrupted with Triton and the number of cfu was determined.

Association and invasion assays were performed three times (two wells per test). For statistical analyses, counts were transformed to their $\log _{10}$ and analyses of variance (ANOVA) performed, followed by standard $t$ tests.

\section{Fluorescent actin staining}

The fluorescent actin staining (FAS) patterns were investigated following the method described by Knutton et al. [27]. Bovine kidney, trachea, ileum, colon, rectum and HEp-2 cells were grown to confluence on coverslips as described previously [26] and were infected with $1 \times 10^{7}$ bacteria from an overnight culture of EHEC O157 $\mathrm{VT}^{-}$, EPEC O111 and E. coli K12. Monolayers were washed with HBSS, fixed with buffered formalin, permeabilised with Triton $0.1 \%$, probed with a phalloidin-FITC conjugate and mounted on to microscope slides with DPX mountant. Slides were observed by fluorescence microscopy at $\times 1000$ magnification with a Zeiss light microscope (Axiovert 25) equipped with a CONTAX 167MT camera.

\section{Scanning electron microscopy (SEM)}

Confluent monolayers of bovine kidney, trachea, ileum, colon, rectum and HEp-2 cells were prepared on 13mm coverslips within 24-well tissue-culture plates. Monolayers were infected with bacterial strains as described for the association and invasion assays and incubated for $3 \mathrm{~h}$ at $37^{\circ} \mathrm{C} \quad\left(\mathrm{CO}_{2} \quad 5 \%\right)$. Infected monolayers were washed four times with HBSS and replaced with incomplete medium for a further 3-h incubation. Monolayers were washed three times, fixed in glutaraldehyde $3 \%$ and observed by scanning electron microscopy as described previously [28].

\section{Results}

\section{Development of primary bovine cell lines}

Islands of cells were observed microscopically within 7 days and these monolayers were expanded successfully into larger tissue-culture flasks. At the earliest opportunity, the primary cells were detached enzymically from the tissue-culture plastic and secured in liquid nitrogen. A seed stock of 10 vials was prepared for cells originating from the kidney, trachea, ileum, colon and rectum, but cells derived from the rumen were non-viable in tissue culture. Frozen cells were reconstituted successfully and growth characteristics of the cells and morphological observations suggested that these were 'epithelial-like' (Fig. 1).

\section{Interaction of bacteria with cells}

Association and invasion assays demonstrated that each of the three $E$. coli serotypes and $S$. Typhimurium interacted with each of the different bovine cell types. A similar trend was observed for the total number of bacteria associating for each bovine cell type (Fig. 2). E. coli $\mathrm{K} 12$ associated with lowest numbers - between 10- and 100-fold lower, depending on cell type, than EHEC 0157:H7, which adhered with the highest numbers $(p<0.05)$. There were no statistical differences between the association of the EPEC O111 strain and the $S$. Typhimurium strain 3530 with bovine cells derived from the kidney, trachea or colon.

The numbers of bacteria associating with HEp-2 cells showed a similar trend. There were no significant differences between EPEC O111 and $S$. Typhimurium $(p<0.354)$, but differences were significant between the other strains $(p<0.05)$ whereby EHEC O157:H7 adhered with the highest numbers and E. coli K12 the lowest.

More than $10 \%$ of adherent $S$. Typhimurium invaded each of the bovine-derived cell types or HEp-2 cells, whereas in general $<0.1 \%$ of adherent EHEC O157:H7 and EPEC O111 invaded. E. coli $\mathrm{K} 12$ was shown to invade but at the limits of detection and, with the notable exception of bovine kidney cell, significantly 

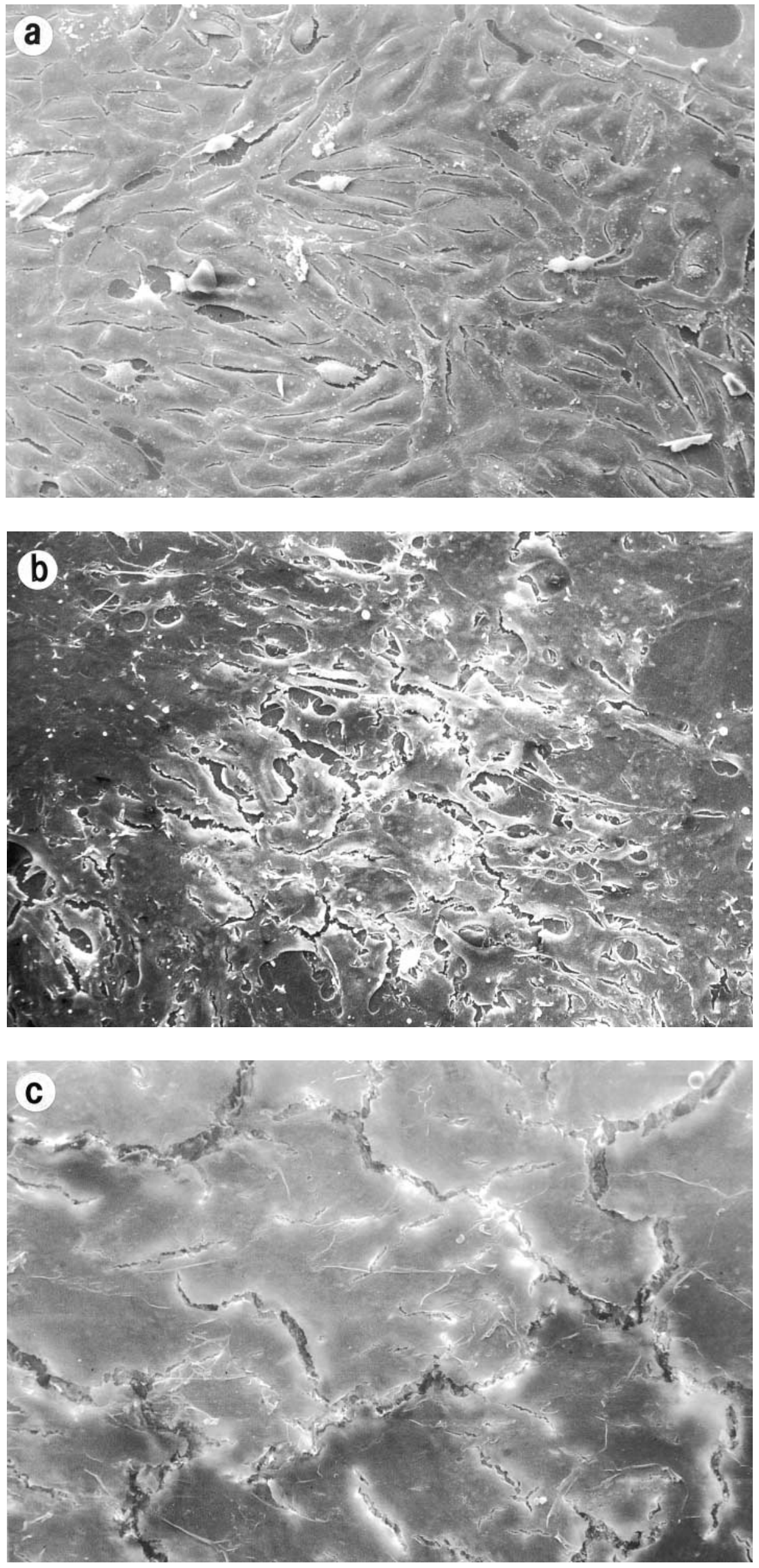

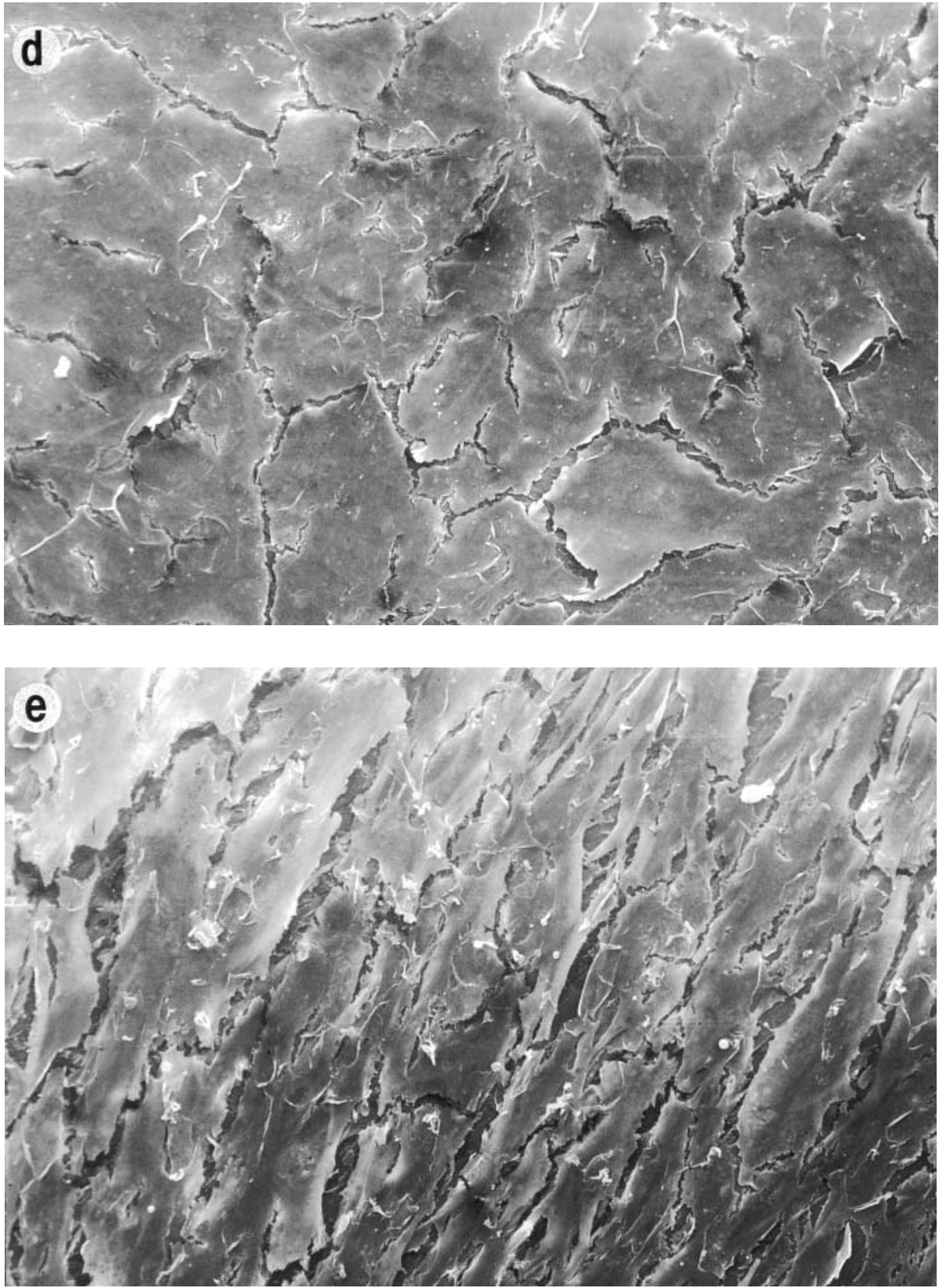

Fig. 1. Electron micrographs of bovine cells derived from (a) kidney, (b) trachea, (c) ileum, (d) colon and (e) rectum. Magnification $\times 280$.

less than the other bacteria $(\mathrm{p}<0.05)$. For invasion with all cell types, the mean counts for $S$. Typhimurium were significantly higher $(\mathrm{p}<0.05)$ than other bacteria.

\section{Electron microscopical analyses of adherence}

Localised adherence by EHEC 0157:H7 and EPEC 0111 was observed on cells derived from bovine kidney, trachea, ileum, colon and rectum and also the HEp-2 cells, whereas a diffuse colonisation pattern was observed with $E$. coli $\mathrm{K} 12$ and $S$. Typhimurium strain 3530 on all cell types. Examples of adherence pattern are shown in Fig. 3 and a description of the type of adherence pattern for each bacterial type with each cell type is listed in Table 1. Densely packed bacterial cell clusters or micro-colonies were formed by EHEC
O157:H7 on all cell types, but were more numerous on cells derived from the colon. Micro-colonies were formed by EPEC O111 on HEp-2 cells but not on primary bovine cells (Table 1). A shrinkage of the cells was observed by electron microscopy following localised adherence by EHEC O157:H7 and EPEC O111 (Fig. 3).

\section{Cytoskeletal re-arrangements}

Interactions of EHEC O157:H7 and EPEC O111 with HEp-2 cells caused a strong localised cytoskeletal rearrangement induced by the polymerisation of actin filaments (Table 2, Fig. 4). With all primary bovine cells, cytoskeletal re-arrangements were observed upon interactions with EHEC O157:H7 and EPEC O111. 
a

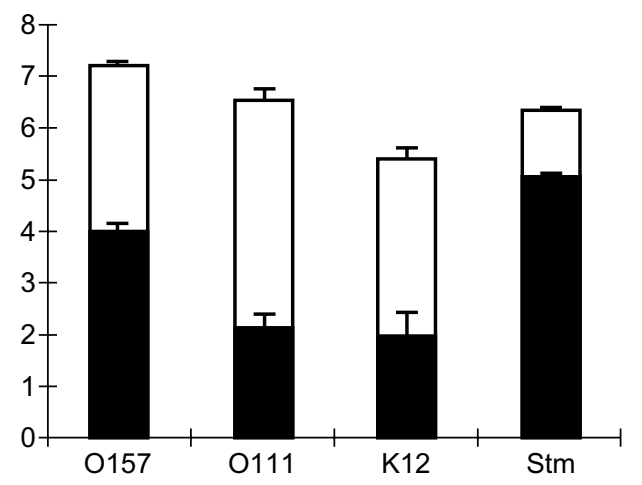

C

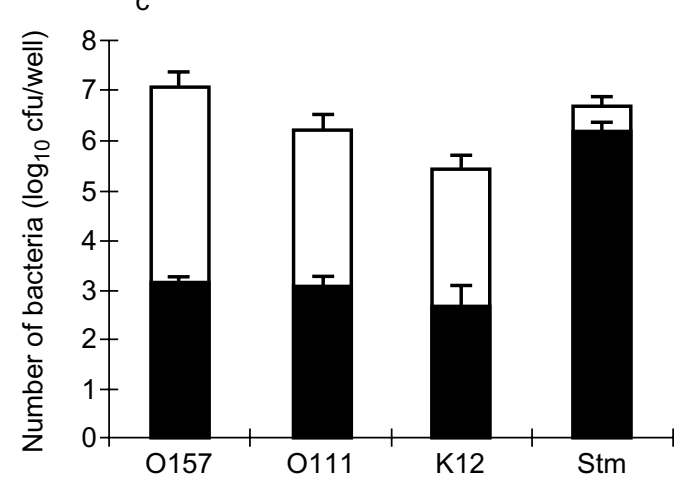

e

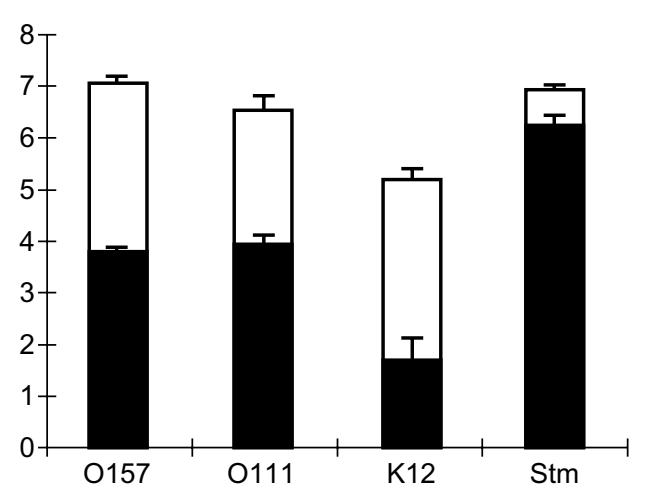

b

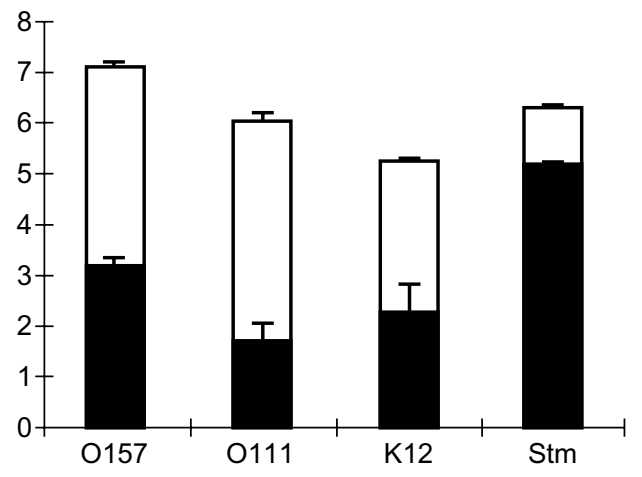

d
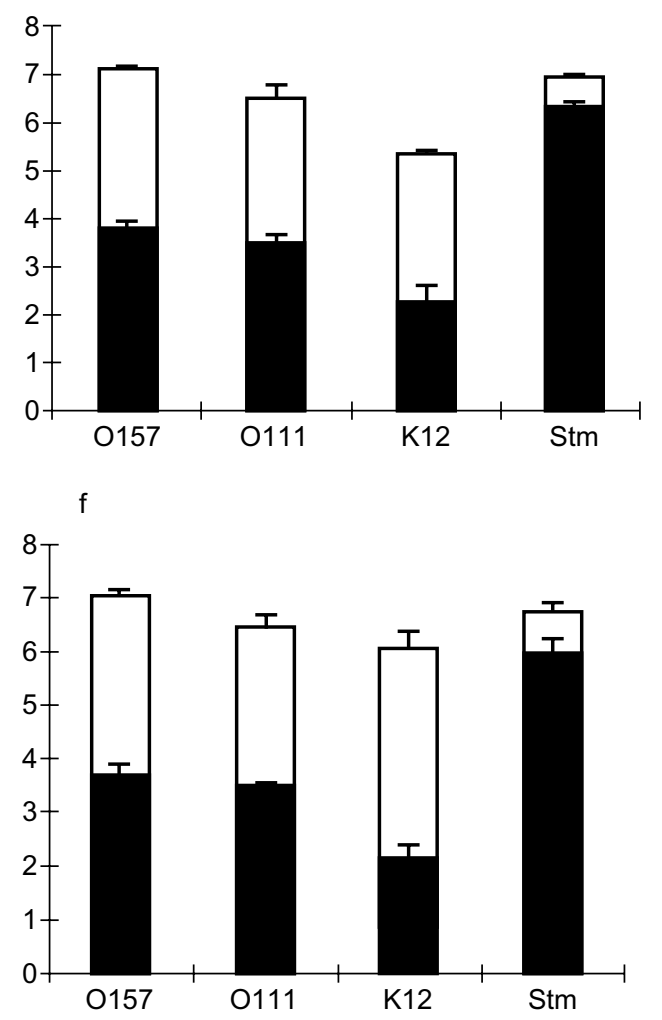

Fig. 2. Association with ( $\square$ ) and invasion of (a) (a) HEp-2 cells, and bovine primary cells derived from (b) kidney, (c) trachea, (d) ileum, (e) colon and (f) rectum, following infection with EHEC O157, EPEC O111, E. coli K12 and $S$. Typhimurium $(\mathrm{Stm})$. Bars $=$ SEM.

However, the intensity of the FAS reaction was greater with EHEC O157:H7 than for EPEC O111. For both EHEC O157:H7 and EPEC O111 the most intensive lesions were observed with HEp-2 cells. Lesions were not observed on primary bovine cells or HEp-2 cells following infection with $E$. coli $\mathrm{K} 12$ or $S$. Typhimurium strain 3530 .

\section{Discussion}

The aim of this study to prepare bovine primary gastrointestinal epithelial-derived cells was achieved and the cells were used to assess adherence and invasion with several test bacteria, including EHEC
O157:H7. To the best of our knowledge this is the first report of the preparation of bovine primary gastrointestinal-derived cells for specific use in studies with EHEC. Other studies have focused primarily on the interaction between EHEC O157 and human-derived cell lines such as Henle, HeLa, HEp-2, T84, HCT-8 and HEL cells as reported by Tarr and Bilge [29]. Cattle are reservoirs of EHEC O157 and yet relatively little is understood of the nature of the interaction between EHEC $\mathrm{O} 157$ and bovine cells, especially as there is a need to understand the mechanisms of persistence in this host.

The morphology of cells derived from each of the five tissue types was consistent with epithelial cells and 

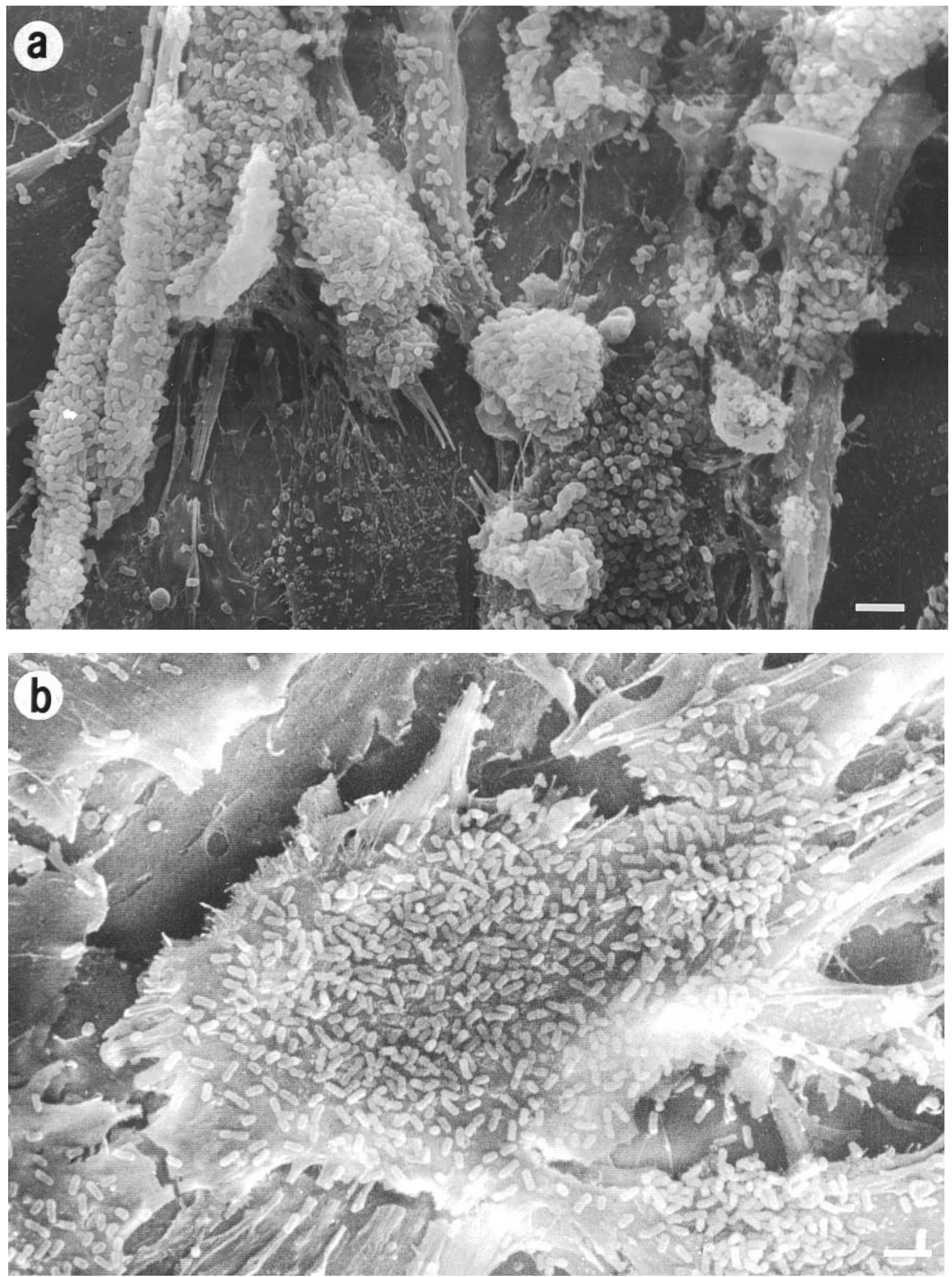

Fig. 3. Scanning electron micrographs showing the patterns of interaction of (a) EHEC O157:H7 strain NCTC 12900 and (b) EPEC O111 strain NM:B171 with primary bovine cells from the colon. Bars $=5 \mu \mathrm{m}$.

microscopic examination taken in conjunction with growth characteristics of the primary cultures indicated that no fibroblastic cells were present in monolayers used for adherence and invasion assays. However, no quantifiable evidence was presented to demonstrate total absence of fibroblastic cells. Thus, it is debatable whether the potential presence of very low numbers of fibroblastic cells may alter the interpretation of the observations.

No significant differences in either adherence or invasion by $S$. Typhimurium were observed between any of the five cell types. $S$. Typhimurium was considered an appropriate positive control serotype 
Table 1. Summary of patterns of interaction of E. coli and $S$. Typhimurium with HEp-2 and bovine primary cells

\begin{tabular}{lcccccc}
\hline & \multicolumn{5}{c}{ Adherence to } \\
\cline { 2 - 7 } & \multicolumn{5}{c}{ Primary bovine cells } \\
\cline { 2 - 7 } Bacterial strain & Kidney & Trachea & Ileum & Colon & Rectum & HEp-2 \\
\hline EHEC O157 strain NCTC12900 & ${ }^{*}$ LA & ${ }^{*}$ LA & ${ }^{*}$ LA & ${ }^{*}$ LA & ${ }^{*}$ LA & ${ }^{*}$ LA \\
EPEC O111 strain NM:B171 & LA & LA & LA & LA & LA & ${ }^{*}$ LA \\
E. coli K12 strain DH5 $\alpha$ & DA & DA & DA & DA & DA & DA \\
$S$. Typhimurium strain 3530 & DA & DA & DA & DA & DA & DA \\
\hline LA, localised adherence; DA, diffuse adherence. & & & & \\
*Formation of densely packed micro-colonies.
\end{tabular}

Table 2. Fluorescent actin staining (FAS) of bovine primary cells and HEp-2 following interaction with $E$. coli and $S$. Typhimurium

\begin{tabular}{lcccccc}
\hline & & \multicolumn{5}{c}{ FAS effects demonstrated in } \\
\cline { 2 - 6 } & & \multicolumn{7}{c}{ Primary bovine cells } \\
\cline { 2 - 7 } Bacterial strain & Kidney & Trachea & Ileum & Colon & Rectum & HEp-2 \\
\hline EHEC O157 strain NCTC12900 & ++ & ++ & ++ & ++ & ++ & +++ \\
EPEC O111 strain NM:B171 & + & + & + & + & + & +++ \\
E. coli K12 strain DH5 $\alpha$ & - & - & - & - & - & - \\
$S$. Typhimurium strain 3530 & - & - & - & - & - & - \\
\hline,+++ high intensity FAS lesions formed;,++ medium intensity FAS lesions formed; + low
\end{tabular}
intensity FAS lesions formed; -, no FAS lesions formed.

because of its association with bovine calf diarrhoea [30]. Consistent with reports with other cells and cell lines, $>10 \%$ of adherent $S$. Typhimurium invaded [31]. E. coli $\mathrm{K} 12$ strain $\mathrm{DH} 5 \alpha$ adhered less well than all other bacterial isolates tested and invasion was detectable, but only at the level of sensitivity of the methods used. E. coli $\mathrm{K} 12$ is regarded as non-invasive and it is possible that incubation for $3 \mathrm{~h}$, as done in these studies, may be associated with invasion. This finding was either an artefact of the method or, under the conditions used, these cells did facilitate bacterial uptake or were susceptible to invasion by as yet unknown mechanisms.

Of the two pathogenic E. coli serotypes tested, the EHEC O157:H7 isolate adhered in significantly greater numbers to all bovine tissue types than the EPEC O111 isolate or the $S$. Typhimurium control strain. This suggests that EHEC O157:H7 may be particularly well adapted to adhere to bovine cells. However, considerable care must be taken in drawing such conclusions because these studies were performed with single isolates and the findings may not be representative of the various serotypes tested. Further studies with a library of $\mathrm{O} 157: \mathrm{H} 7$ isolates of different provenance in adherence and invasion assays are in hand to assess this possibility. Matthews et al. [32] demonstrated adherence and invasion of bovine MAC$\mathrm{T}$ mammary secretory and MDBK kidney epithelial cell lines by 12 distinct EHEC O157:H7 strains. Thus, invasion of the bovine cells in this study was anticipated, albeit significantly lower by a factor of 3-4-fold than for $S$. Typhimurium. MDBK cells are an established line and it would be of interest to compare the adherence and invasion patterns of the bacterial strains used in this study between these and the primary kidney cells derived here. Invasion, as in passing the gut barrier, has yet to be reported in any whole animal studies and invasion of primary cells by EHEC O157:H7 indicates a limitation in the use of these cells as a model. For example, primary cells were in an inappropriate physiological state in vitro and, therefore, susceptible to invasion. However, this should not invalidate their use for more detailed studies on the initial interaction between EHEC O157:H7 and bovine cells.

The localised adherence (LA) pattern of EPEC and EHEC has been characterised previously in established cell lines [27]. The present study demonstrated that EHEC O157 gave an intense FAS reaction on all bovine tissue types, and that adherence was typical with well-developed localised micro-colony formation with some additional diffuse adherence. Similar observations have been made regarding the interaction of EHEC O157:H7 and human cells [10,33, 34]. In contrast, EPEC O111 gave an intense FAS reaction on HEp-2, but weaker intensity with bovine primary cells, and adherence was typically localised without microcolony formation, except on HEp-2 cells only. The clear phenotypic differences observed between the EHEC and EPEC strains tested may support the conclusion that EHEC were better adapted to colonising bovine tissues than EPEC. Whilst this is an unsurprising conclusion, because EPEC are primarily human pathogens, the data also suggest that these 

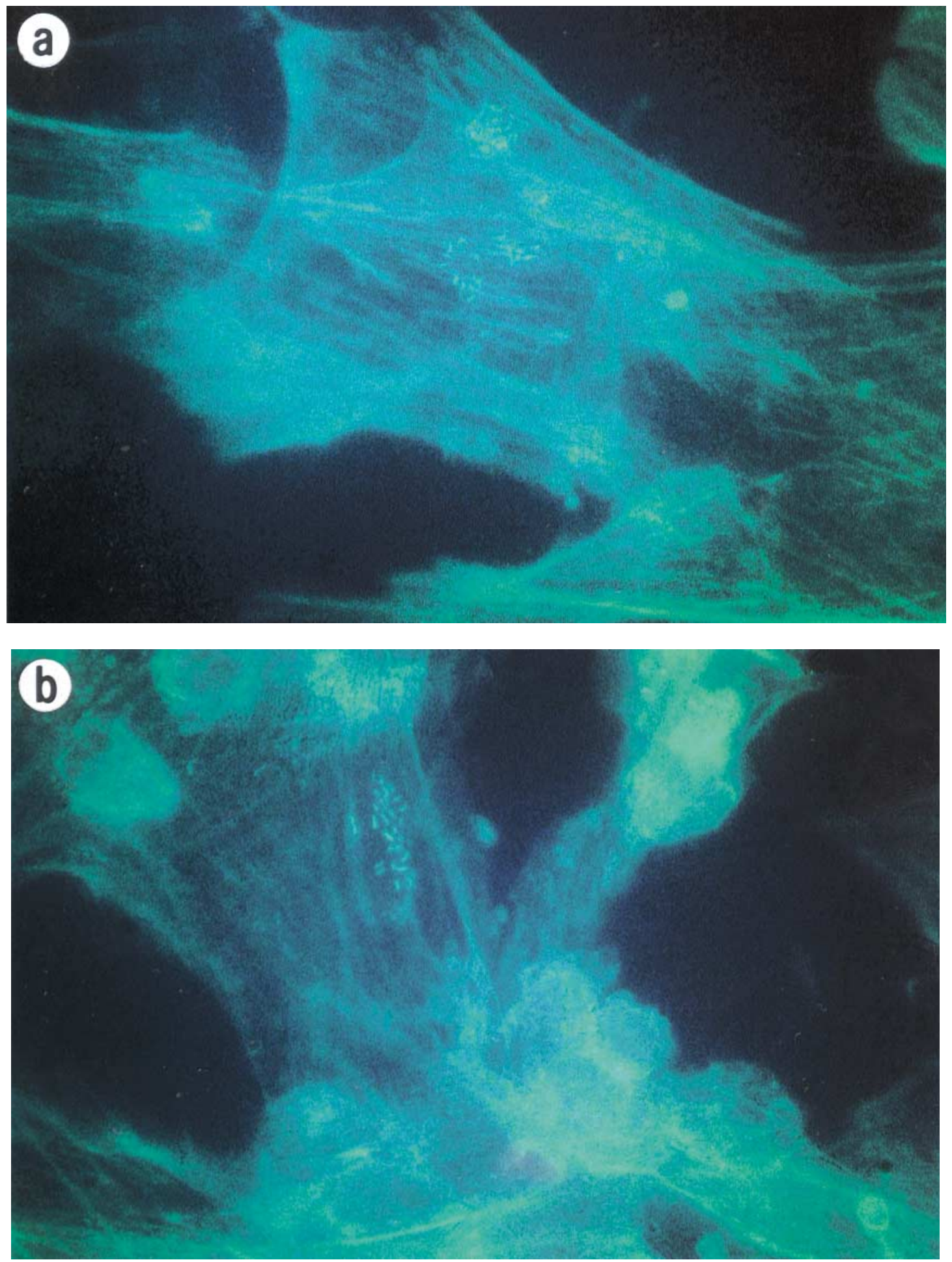

Fig. 4. Fluorescent actin staining of primary bovine cells from the colon following interaction with (a) EHEC O157:H7 strain NCTC 12900 and (b) EPEC O111 strain NM:B171. Magnification $\times 1000$.

primary cells may possess bovine-specific factors that enhance EHEC adherence.

Phillips et al. [35] demonstrated a cascade of complex events leading to intimate attachment of EPEC O111 and EPEC O127 to HEp-2 cells. These authors showed transient elaboration of microvillus-like projections (MLPs) emanating from the HEp-2 cells that appeared within $20 \mathrm{~min}$ of the addition of bacteria to the cells. By $60 \mathrm{~min}$, the MLPs had confined and recruited bacteria that would subsequently become bound intimately. This process was intimin dependent. Furthermore, these processes were not observed in similar experiments with $\mathrm{CaCo}$ cells. It would be interesting to test whether similar events occur in the interaction between EHEC $\mathrm{O} 157$ and bovine-derived cells. Adu-Bobie et al. [36] established that there are at least four intimin types $(\alpha, \beta, \gamma$ and $\delta)$ of which the variant $\mathrm{C}$-terminal portion is associated with tissue tropism [37-39]. EPEC possess $\beta$-intimin and attach 
preferentially to the mucosa of the small intestine, whereas EHEC possess $\gamma$-intimin and attach preferentially to the mucosa of the large intestine. However, no obvious differences in adherence of EHEC O157:H7 to bovine primary cell cultures correlated with this observation.

We conclude that adherence of EHEC O157:H7 to the bovine cells was, in part, dependent upon the locus for enterocyte effacement because actin re-arrangement was visualised by FAS, invariably at the site of microcolony formation. This observation is compatible with the development of attaching and effacing lesions by EHEC O157:H7 in bovine colonic explant experiments [40]. However, there were diffusely adherent EHEC O157:H7 bacteria that were not associated with actin re-arrangement and the question arises as to what mechanism mediated this adherence. The present studies were not performed in the presence of mannose to block the type 1 fimbrial adhesin (FimH) activity. Although Durno et al. [41] suggested that type 1 fimbriae mediated mannose sensitive adherence of EHEC O157:H7 strain CL-49 to epithelial cells, Sajjan and Forstner [42] and more recently Enami et al. [43] showed that strain CL-49 was unique because of $>40$ other EHEC O157 strains tested none elaborated type 1 fimbriae in vitro. The EHEC O157:H7 strain used in the present study lacked type 1 fimbriae (data not shown). However, it remains unclear whether EHEC O157:H7 may express type 1 fimbriae in vivo. Both Bilge et al. [33] and Cockerill et al. [34] demonstrated that transposon mutants unable to elaborate O157 LPS were more adherent to HEp-2 cells than the wild-type. Therefore, it seems unlikely that either lipopolysaccharide or type 1 fimbriae played a role in adherence and it remains possible that EHEC O157:H7 adherence to bovine tissues may be mediated by both locus for enterocyte effacement-dependent and independent pathways, as previously suggested by Tarr and Bilge [29].

This work was funded by the Ministry of Agriculture, Fisheries and Food, UK (Project code OZ0133). The authors would like to thank Dr A. Cookson for helpful discussions and Mr A.R. Sayers for statistical analyses.

\section{References}

1. Riley LW, Remis RS, Helgerson SD et al. Hemorrhagic colitis associated with a rare Escherichia coli serotype. $N$ Engl J Med 1983; 308: 681-685.

2. Karmali MA, Steele BT, Petric M, Lim C. Sporadic cases of haemolytic-uraemic syndrome associated with faecal cytotoxin and cytotoxin-producing Escherichia coli in stools. Lancet 1983; 1: 619-620.

3. Smith HR, Scotland SM. Isolation and identification methods for Escherichia coli $\mathrm{O} 157$ and other vero cytotoxin producing strains. J Clin Pathol 1993; 46: 10-17.

4. Boyce TG, Swerdlow DL, Griffin PM. Escherichia coli O157:H7 and the hemolytic uremic syndrome. N Engl J Med 1995; 333: 364-368.

5. Swinbanks D. Japan shuns radishes after "possible link" to $E$. coli. Nature 1996; 382: 567.

6. Nataro JP, Kaper JB. Diarrheagenic Escherichia coli. Clin Microbiol Rev 1998; 11: 142-201.
7. Karch H, Heesemann J, Laufs R, O'Brien AD, Tacket CO, Levine MM. A plasmid of enterohemorrhagic Escherichia coli O157:H7 is required for expression of a new fimbrial antigen and for adhesion to epithelial cells. Infect Immun 1987; 55: 455-461.

8. Toth I, Cohen ML, Rumschlag HS et al. Influence of the 60megadalton plasmid on adherence of Escherichia coli $\mathrm{O} 157$ and genetic derivatives. Infect Immun 1990; 58: 1223-1231.

9. Ashkenazi S, Larocco M, Murray BE, Cleary TG. The adherence of verocytotoxin-producing Escherichia coli to rabbit intestinal cells. J Med Microbiol 1992; 37: 304-309.

10. Sherman P, Soni R, Petric M, Karmali M. Surface properties of the Vero cytotoxin-producing Escherichia coli O157:H7. Infect Immun 1987; 55: 1824-1829.

11. Junkins AD, Doyle MP. Comparison of adherence properties of Escherichia coli $\mathrm{O} 157: \mathrm{H} 7$ and a 60-Megadalton plasmid-cured derivative. Curr Microbiol 1989; 19: 21-27.

12. Donnenberg MS, Tzipori S, McKee ML, O’Brien AD, Alroy J, Kaper JB. The role of the eae gene of enterohemorrhagic Escherichia coli in intimate attachment in vitro and in a porcine model. J Clin Invest 1993; 92: 1418-1424.

13. Kenny B, Finlay BB. Intimin-dependent binding of enteropathogenic Escherichia coli to host cells triggers novel signaling events, including tyrosine phosphorylation of phospholipase C $\chi 1$. Infect Immun 1997; 65: 2528-2536.

14. Knutton S, Rosenshine I, Pallen $\mathrm{M}$ et al. A novel EspAassociated surface organelle of enteropathogenic Escherichia coli involved in protein translocation into epithelial cells. EMBO J 1998; 17: 2166-2176.

15. Lee CA. Type III secretion systems: machines to deliver bacterial proteins into eukaryotic cells? Trends Microbiol 1997; 5: $148-156$.

16. Griffin PM, Tauxe RV. The epidemiology of infections caused by Escherichia coli O157, other enterohemorrhagic Escherichia coli and the associated hemolytic uraemic syndrome. Epidemiol Rev 1991; 13: 60-98.

17. Tzipori S, Gunzer F, Donnenberg MS, de Montigny L, Kaper $\mathrm{JB}$, Donohue-Rolfe A. The role of the eaeA gene in diarrhea and neurological complications in a gnotobiotic piglet model of enterohemorrhagic Escherichia coli infection. Infect Immun 1995; 63: 3621-3627.

18. McKee ML, Melton-Celsa AR, Moxley RA, Francis DH, O'Brien AD. Enterohemorrhagic Escherichia coli O157:H7 requires Intimin to colonize the gnotobiotic pig intestine and to adhere HEp-2 cells. Infect Immun 1995; 63: 3739-3744.

19. Brown CA, Harmon BG, Zhao T, Doyle MP. Experimental Escherichia coli $\mathrm{O} 157$ carriage in calves. Appl Environ Microbiol 1997; 63: 27-32.

20. Hancock DD, Besser TE, Kinsel ML, Tarr PI, Rice DH, Paros MG. The prevalence of Escherichia coli O157:H7 in dairy and beef cattle in Washington State. Epidemiol Infect 1994; 113: 199-207.

21. Besser TE, Hancock DD, Prichett LC, McRae EM, Rice DH, Tarr PI. Duration of detection of fecal excretion of Escherichia coli O157:H7 in cattle. J Infect Dis 1997; 175: 726-729.

22. Dean-Nystrom EA, Bosworth BT, Cray WC, Moon HW. Pathogenicity of Escherichia coli $\mathrm{O} 157: \mathrm{H} 7$ in the intestines of neonatal calves. Infect Immun 1997; 65: 1842-1848.

23. Dean-Nystrom EA, Bosworth BT, Moon HW. Pathogenesis of Escherichia coli O157:H7 in weaned calves. In: Paul PS, Francis DH (eds) Mechanisms in the pathogenesis of enteric diseases 2. (Advances in Experimental Medicine and Biology, vol 473). New York, Kluwer. 1999: 173-177.

24. Paulozzi LJ, Johnson KE, Kamahele LM, Clausen CR, Riley LW, Helgerson SD. Diarrhea associated with adherent enteropathogenic Escherichia coli in an infant and toddler center, Seattle, Washington. Pediatrics 1986; 77: 296-300.

25. Youngner JS. Monolayer tissue cultures. 1. Preparation and standardization of suspension of trypsin-dispersed monkey kidney cells. Proc Soc Exp Biol Med 1954; 85: 202-205.

26. Dibb-Fuller MP, Allen-Vercoe E, Thorns CJ, Woodward MJ. Fimbriae- and flagella- mediated association with and invasion of cultured epithelial cells by Salmonella enteritidis. Microbiology 1999; 145: 1023-1031.

27. Knutton S, Baldwin T, Williams PH, McNeish AS. Actin accumulation at sites of bacterial adhesion to tissue culture cells: basis of a new diagnostic test for enteropathogenic and enterohemorrhagic Escherichia coli. Infect Immun 1989; 57: $1290-1298$. 
28. La Ragione RM, Cooley WA, Woodward MJ. The role of fimbriae and flagella in the adherence of avian strains of Escherichia coli $\mathrm{O} 78: \mathrm{K} 80$ to tissue culture cells and tracheal and gut explants. J Med Microbiol 2000; 49: 327-338.

29. Tarr PI, Bilge SS. Intimin-independent adherence mechanisms of Escherichia coli $\mathrm{O} 157: \mathrm{H} 7$ and other Shiga toxin-producing E. coli strains. In: Kaper JB, O'Brien AD (eds) Escherichia coli $\mathrm{O} 157: \mathrm{H} 7$ and other Shiga toxin-producing E. coli strains. Washington, DC, ASM Press. 1998: 157-162.

30. Wray C, Davies RH. Salmonella infections in cattle. In: Wray C, Wray A (eds) Salmonella in domestic animals. Wallingford, CABI Publishing. 2000: 169-190.

31. Gahring LC, Heffron F, Finlay BB, Falkow S. Invasion and replication of Salmonella typhimurium in animal cells. Infect Immun 1990; 58: 443-448.

32. Matthews KR, Murdough PA, Bramley AJ. Invasion of bovine epithelial cells by verocytotoxin-producing Escherichia coli O157:H7. J Appl Bacteriol 1997; 82: 197-203.

33. Bilge SS, Vary JC, Dowell SF, Tarr PI. Role of the Escherichia coli $\mathrm{O} 157: \mathrm{H} 7 \mathrm{O}$ side chain in adherence and analysis of an $\mathrm{rfb}$ locus. Infect Immun 1996; 64: 4795-4801.

34. Cockerill F, Beebakhee G, Soni R, Sherman P. Polysaccharide side chains are not required for attaching and effacing adhesion of Escherichia coli O157:H7. Infect Immun 1996; 64: 3196-3200.

35. Phillips AD, Giròn J, Hicks S, Dougan G, Frankel G. Intimin from enteropathogenic Escherichia coli mediates remodelling of the eukaryotic cell surface. Microbiology 2000; 146: 1333-1344.

36. Adu-Bobie J, Frankel G, Bain C et al. Detection of intimins $\alpha$, $\beta, \gamma$ and $\delta$, four intimin derivatives expressed by attaching and effacing microbial pathogens. J Clin Microbiol 1998; 36: $662-668$.

37. Hicks S, Frankel G, Kaper JB, Dougan G, Phillips AD. Role of intimin and bundle-forming pili in enteropathogenic Escherichia coli adhesion to pediatric intestinal tissue in vitro. Infect Immun 1998; 66: 1570-1578.

38. Frankel G, Candy DCA, Everest P, Dougan G. Characterization of the C-terminal domains of intimin-like proteins of enteropathogenic and enterohaemorrhagic Escherichia coli, Citrobacter freundii and Hafnia alvei. Infect Immun 1994; 62: $1834-1842$.

39. Kelly G, Prasannan S, Daniell S et al. Structure of the celladhesion fragment of intimin from enteropathogenic Escherichia coli. Nature Struct Biol 1999; 6: 313-318.

40. Baehler AA, Moxley RA. Escherichia coli O157:H7 induces attaching-effacing lesions in large intestinal mucosal explants from adult cattle. FEMS Microbiol Lett 2000; 185: 239-242.

41. Durno C, Soni R, Sherman P. Adherence of vero cytotoxinproducing Escherichia coli serotype O157:H7 to isolated epithelial cells and brush border membranes in vitro; role of type 1 fimbriae (pili) as a bacterial adhesin expressed by strain CL-49. Clin Invest Med 1989; 12: 194-200.

42. Sajjan SU, Forstner JF. Characteristics of binding of Escherichia coli serotype O157:H7 strain CL-49 to purified intestinal mucin. Infect Immun 1990; 58: 860-867.

43. Enami M, Nakaone N, Honma Y, Kakinohama S, Kudaka J, Iwanaga M. Expression of type I pili is abolished in verotoxinproducing Escherichia coli O157. FEMS Microbiol Lett 1999; 179: $467-472$. 